\title{
FE SIMULATION OF BIRD STRIKE TESTS OF COMPOSITE PANELS IN MSC.SOFTWARE
}

\begin{abstract}
V.Symonov*
Abstract: In this article, the author shows the result of an attempt to tune the parameters of finite element simulations of bird strikes on a composite panel based on the results of real bird strike tests. The main objective of this study was to find the finite element model parameters, which would provide the best correlation between the experiments and simulations. For these purpose two different software MSC.Nastran and MSC.Dytran and two different methods Lagrangian-Eulerian and Smooth Particles Hydrodynamics were used for simulations. The model and simulation parameters were varied and the simulations results were compared with the tests results. The study has shown that the simple model of a composite panel, which was meshed with CQUAD4 and CTRIA shell elements, does not allow to accurately simulate the deflections and the damage of the panel occurred during the bird strike.
\end{abstract}

Keywords: bird strike, finite element simulation, MSC.Software, Lagrangian-Eulerian, smooth particles hydrodynamic, composite panel

\section{Introduction}

Nowadays, the finite element (FE) simulations of materials and structures tests dramatically reduce the budget, time and human resources required for the structure design stage. One of the main aspects of a successful simulation of a test is the correct customization/tuning of material models and parameters, which control the simulation process. The material models can be customized based on material tests and the simulation control parameters - based on tests of simple structural elements like panel, spar, etc.

There exist several explicit programs and codes, which can simulate such dynamic problems like bird strike - LS-Dyna, PamCrash, Abaqus, MSC.Dytran, MSC.Nastran SOL700, etc. The precision of simulated results highly depends on the methods used for simulation (Georgiadis at el., 2008 and Heimbs, 2011) and the model complexity (Johnson, 2001, Moncayo J., 2007 and Mališ 2007). However, industrial problems require as simple models as possible and usually shell FE models are used.

A series of bird strike tests and simulations were performed during this work. The test specimens were the panels made of carbon fabric described in the next section.

\section{Panel geometry and material}

A simplified drawing of the panel is shown in Fig. 1. The material used for panels lay-up is the carbon fabric Hexply AGP193PW/8552S RC40. The baseline material properties used for simulations are listed in Tab. 1. The panels' laminate consisted of 18 layers with $\left[45^{\circ}, 90^{\circ},-45^{\circ}, 0^{\circ}\right]_{\mathrm{ns}}$ stacking sequence.

\section{Bird strike tests}

The bird strike tests were performed in the framework of the TAČR project TE02000032 named Advanced Aerostructures Research Center at the VZLU test laboratory. The main parameters of the tests and the test panels are provided in Tab. 2. The fresh dead $1 \mathrm{~kg}$ chickens were used as projectiles during the tests. The test jig and frame for perpendicular impact is shown in Fig. 2.

\footnotetext{
* Ing. Volodymyr Symonov: Institute of Aerospace Engineering, Brno University of Technology, Technická street 2896/2, 616 69, Brno; CZ, symonov@fme.vutbr.cz
} 


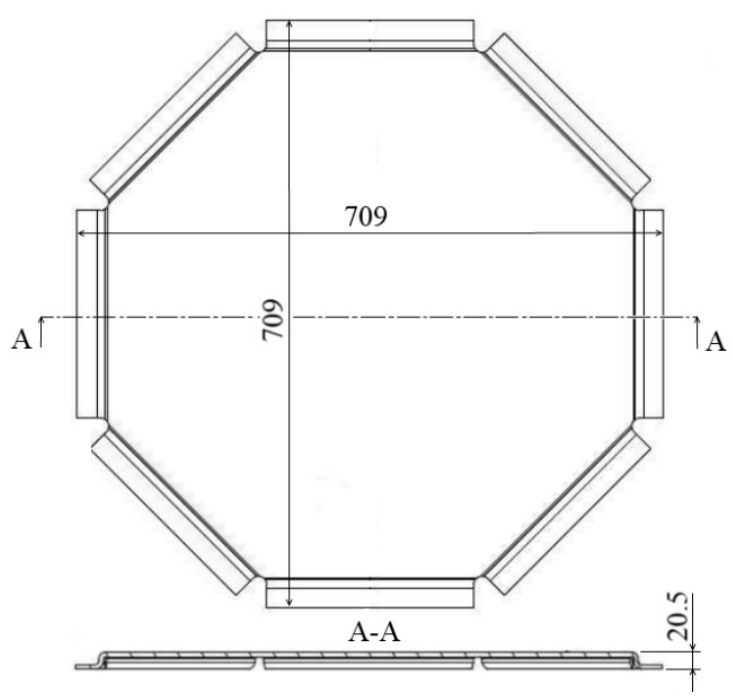

Fig. 1: Geometry of test panel.

Tab. 1: Hexply AGP193PW/8552S RC40 properties.

\begin{tabular}{ccc}
\hline Property & Unit & Value \\
\hline $\mathrm{E}_{11}=\mathrm{E}_{22}$ & $\mathrm{MPa}$ & 60000 \\
\hline $\mathrm{G}_{12}$ & $\mathrm{MPa}$ & 4500 \\
\hline $\mathrm{G}_{13}=\mathrm{G}_{23}$ & $\mathrm{MPa}$ & 3000 \\
\hline$\mu_{12}$ & - & 0,38 \\
\hline $\mathrm{X}_{\mathrm{t}}=\mathrm{Y}_{\mathrm{t}}$ & $\mathrm{MPa}$ & 625 \\
\hline $\mathrm{X}_{\mathrm{c}}=\mathrm{Y}_{\mathrm{c}}$ & $\mathrm{MPa}$ & 738 \\
\hline $\mathrm{S}$ & $\mathrm{MPa}$ & 100 \\
\hline $\mathrm{ILSS}$ & $\mathrm{MPa}$ & 66 \\
\hline $\mathrm{t}$ & $\mathrm{mm}$ & 0,21 \\
\hline
\end{tabular}

\section{FE simulations of high-speed bird strike}

For bird strike modeling and simulation, two different software MSC.Dytran and MSC.Nastran (SOL700) and two different methods Lagrangian-Eulerian (LE) and Smooth Particles Hydrodynamics (SPH) were used. Modeling of test panels was done with help of 2D shell elements CQUAD4 and CTRIA with average size of $15 \mathrm{~mm}$. The panel geometry corresponds to Fig. 1. The boundary conditions of the panel model all nodes translations at the panel rim were fixed. The shape of the bird in accordance with the recommendations of Heimbs (2011) is cylinder with hemispheric ends. The length to diameter aspect ratio is $2: 1$. The volume and certain dimensions can be calculated from the weight of the bird.

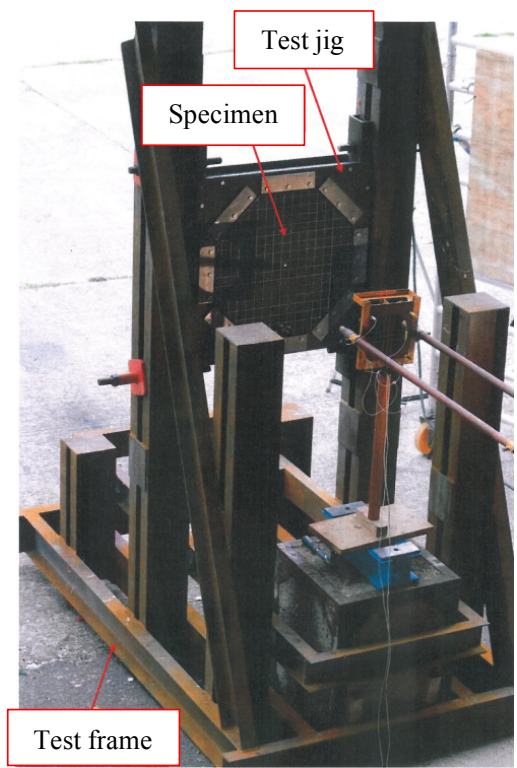

Fig. 2: Test frame and jig
Tab. 2: Main parameters of the tests and the test panels

\begin{tabular}{cccc}
\hline$\#$ & $\begin{array}{c}\text { Panel } \\
\text { thickness, } \\
\mathbf{m m}\end{array}$ & $\begin{array}{c}\text { Initial bird } \\
\text { speed, } \mathbf{k m} / \mathbf{h}\end{array}$ & $\begin{array}{c}\text { Impact } \\
\text { angle, } \\
\mathbf{d e g}\end{array}$ \\
\hline 1 & $3.6-3.7$ & 227 & 90 \\
\hline 2 & $3.6-3.7$ & 333 & 90 \\
\hline 3 & $3.6-3.75$ & 350 & 30 \\
\hline 4 & $3.6-3.7$ & 429 & 30 \\
\hline 5 & $3.6-3.7$ & 487 & 30 \\
\hline 6 & $3.7-3.8$ & 493 & 30 \\
\hline 7 & $3.6-3.7$ & 520 & 30 \\
\hline 8 & $3.7-3.8$ & 604 & 30 \\
\hline
\end{tabular}

\subsection{FE model for MSC.Dytran simulations}

MSC.Dytran impact simulations using LE method were performed for all cases from Tab. 2. The air and the bird were modeled by 3D Euler elements MM/Hydro (PEULER1) and materials Idial Gas (DMAT, EOSGAM) and LinFluid (DMAT, EOSPOL). The air density was taken $1.1848 \mathrm{~kg} / \mathrm{m}^{3}$ and the adiabatic exponent -1.4 . The volume elastic modulus $-2200 \mathrm{MPa}$. The composite material was defined by the MAT8A and the laminate - by PCOMPG. 


\subsection{FE model for MSC.Nastran simulations}

MSC.Nastran (SOL700) impact simulations were performed only for cases 2 and 6 from Tab. 2 by LE method and for cases 5, 7 and 8 by SPH method. The composite material and the laminate of the panel were modeled by MATD058 and PCOMPG cards respectively.

In case of SPH the bird was modeled by 0D elements CSPH. MATD010 and MATD009 were tried for modeling the bird material. The relations between particles within the bird model were defined by the Gruneisen Equation of State (EOSGRUN). The initial velocity of the particles was defined by the TCID card (Transient Analysis Initial Conditions with Increment Options), which allow to define the velocity of taken nodes in a selected coordinate system.

Definition of parameters for particles computation is important also. It is defined with help of SPHDEF card. The number of cycles between particles rearrangement $(\mathrm{NCBS}=10)$ and time for death of the particles, DT - it is equal or less than the full time of simulation. In addition, the parameter for the initial number of neighboring particles, MEMORY, was defined - it is equal to the entire number of particles.

\section{Comparison of bird strike tests and FE simulations results}

The maximum deflection profile in the A-A cross section (see Fig. 1) and the damage extent were compared. The best correlation of the deflection in case of MSC.Dytran simulation occurred at askew impact in the cases 5 and 8 (Tab. 2) and the worst at perpendicular impact in the case 2 (see Fig. 3). Maximum damage was occurred in the case 8 at askew impact with initial bird velocity of $604 \mathrm{~km} / \mathrm{h}$. The comparison of the experiment and MSC.Dytran simulation results is shown in Fig. 4.

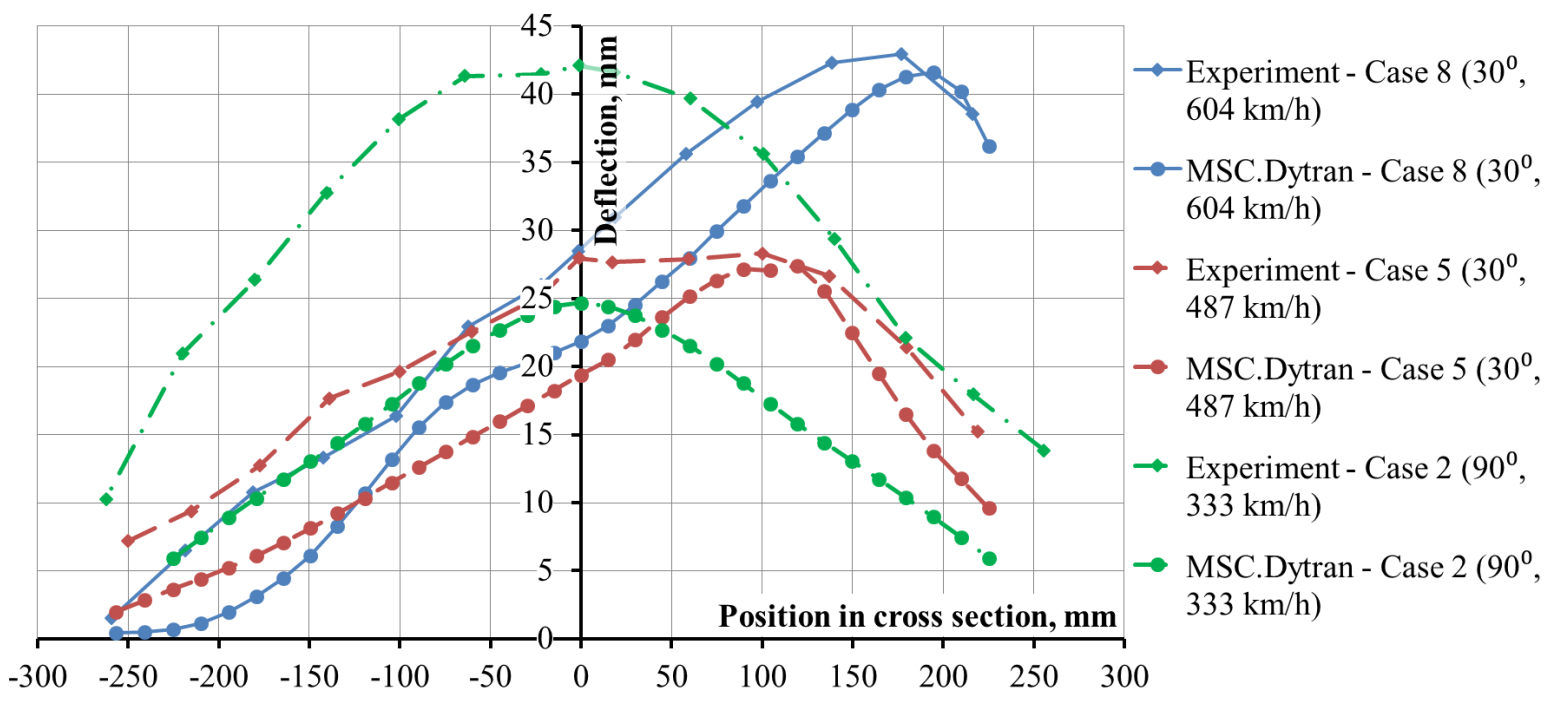

Fig. 3: Comparison of maximum deflection profile

\section{Partial parametric study of FE model and used methods and software}

In order to understand the influence of parameters of FE model and used simulation methods and software on the simulation results a partial parametric study was performed. The varied parameters for MSC.Dytran were the following: bird density $\left(800-900 \mathrm{~kg} / \mathrm{m}^{3}\right)$, contact thickness $(0-$ half of the panel thickness), Young modulus of the composite material $(55-60 \mathrm{GPa})$, composite material strength - tensile, compressive, shear $(80-100 \%)$. In case of MSC.Nastran, the parameters were as follows: bird density (800 - $900 \mathrm{~kg} / \mathrm{m} 3)$, contact friction coefficient $(0-0.5)$, Young modulus of the composite material $(55-60$ $\mathrm{GPa}$ ), interlaminar shear modulus of the composite material ( $1-3 \mathrm{GPa})$, also two different material models were tried for bird (MATD009 and MATD010), in case of SPH, the number of particles was varied too.

The study has shown that the varied parameters do not influence significantly the results of the simulations, except the bird density in SPH method. Moreover, MSC.Nastran SOL700 does not allow to estimate the extent of damage at least with a little reliability. In two of three investigated cases a significant damage occurred during the tests, however, the simulations have not shown any damage. In the third case, the damage predicted by the simulation is much more dramatic than it was in the test.

Moreover, unfortunately MCS.Nastran SOL700 does not allow to get failure indexes for composite or its layers within simulation results. 


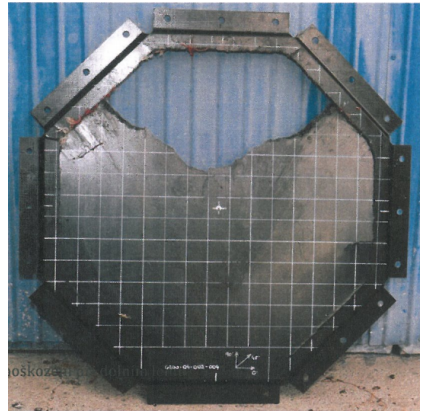

Experiment

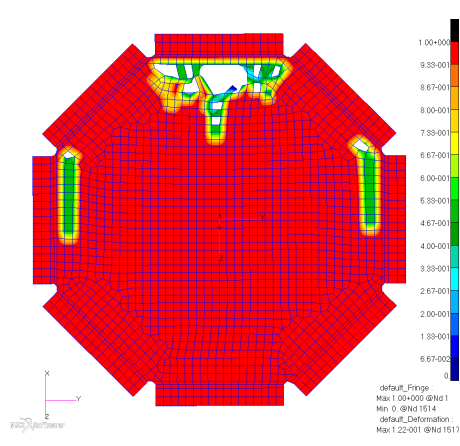

MSC.Dytran

Fig. 4: Comparison of damage extant, impact angle $-30^{\circ}$, initial bird velocity $-604 \mathrm{~km} / \mathrm{h}$

\section{Conclusions}

The performed simulations have shown that in general the maximum deflection of the panel does not have good correlation with experiment. The correlation error of the deflection is in the range of $12-41 \%$ except two cases. It is almost the same for simulations performed by MSC.Dytran (EL method) and MSC.Nastran SOL700 (EL and SPH methods). Varying the model and simulation parameters such as bird density, inplane and interlaminar stiffness of the panel, contact thickness, composite material strength and the contact friction coefficient do not significantly influence the simulation results.

The simulations in MSC.Dytran have a partial correlation with experiment in sense of damage prediction. In the most of cases, the simulation allows predicting the damage extent. On the other hand, in general, the simulations do not allow predicting the damage position.

MSC.Nastran SOL700 simulations using LE method give even worse results.

The most simple and fast for simulation of bird impact is the SPH method with help of MSC.Nastran SOL700. However, it also does not give good correlation with experiment. The damage extent can be tuned by varying the bird model density, but varying of the other parameters does not influence the precision of predicting the damage position and maximum deflection.

\section{Acknowledgement}

This work was done with the financial support of the next projects: NETME Centre built in the frame NETME Centre "New Technologies for Mechanical Engineering" (Reg. No. CZ.1.05/2.1.00/01.0002) with the financial support from the Operational Program Research and Development for Innovations; TE02000032 "Advanced Aerostructures Research Centre" financed by the Technology Agency of the Czech Republic.

\section{References}

Georgiadis, S., Gunnion A.J., Thomson, R.S. and Cartwright, B.K. (2008) Bird-strike simulation for certification of the Boeing 787 composite moveable trailing edge, 86, pp. 258-268. SSN: 0263-8223.

Heimbs, S. (2011) Computational methods for bird strike simulations: A review. Computers and Structures, 89, pp. 2093-2112. ISSN: 0045-7949.

Johnson, A.F., Pickett, A.K., Rozycki, P. (2001) Computational methods for predicting impact damage in composite structures. Composites Science and Technology, 61. pp. 2183-2192.

Mališ, M. (2007). Impact Analysis of the Rigid Body on Thin-walled Aluminium Structure with Considering of the Stochastic Material Properties. Letecký zpravodaj, 2007, 3, p. 65-67. ISSN: 1211-877X.

Moncayo J., E.D., Wagner, H. and Drechsler, K. (2007) Benchmarks for Composite Delamination Using LS-Dyna 971: Low Velocity Impact, in: Proceedings 6. LS-DYNA Anwenderforum, Rfankenthal, DYNAmore, Stuttgart, pp. D-I-13 - D-I-22. 